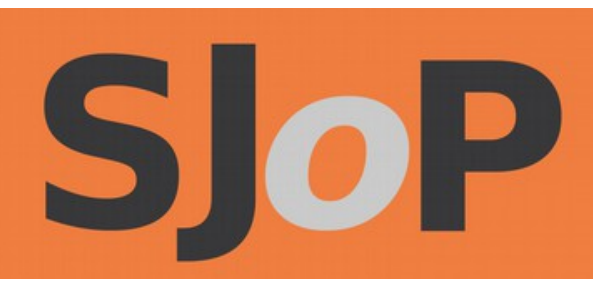

Book review: Book review: Acting Shakespeare's language, by Andy Hinds

\title{
MARC SILBERSCHATZ
}

The Scottish Journal of Performance

Volume 2, Issue 2; June 2015

ISSN: 2054-1953 (Print) / ISSN: 2054-1961 (Online)

Publication details: http://www.scottishjournalofperformance.org

To cite this article: Silberschatz, M., 2015. Book review: Acting Shakespeare's language, by Andy Hinds. Scottish Journal of

Performance, 2(2): pp.125-128.

To link to this article: http://dx.doi.org/10.14439/sjop.2015.0202.08

CC This work is licensed under a Creative Commons
Attribution 4.0 International License. See
http://creativecommons.org/licenses/by/4.0/ for details. 


\title{
Book review: Acting Shakespeare's language, by Andy Hinds
}

\author{
MARC SILBERSCHATZ
}

DOI: 10.14439/sjop.2015.0202.08

Publication date: 26 June 2015

Acting Shakespeare's language, by Andy Hinds. London: Oberon Books Ltd, 2015; ISBN: 9781783190089 (£14.99)

In my career as a director and academic, I have often been asked by students, actors and directors to recommend reading about Shakespearean performance. Responding to this is a struggle. An approach to and understanding of Shakespearean performance is something that in many ways cannot be taught. Rather, I believe the key is in the cultivation of individual ownership of practices in the service of artistic identity and values. Though a single text elucidating the practice of performing Shakespeare can never and will never exist, Acting Shakespeare's language belongs on a very short list of texts that will, in almost all cases, support this ownership and prove stimulating and useful to anyone with an interest in the subject.

The focus of the chapters varies, ranging from foundational ideas or practices ('Questions, orders and explanations', pp.1-17), to specific uses of language in Shakespeare ('Thou and you', pp.37-43), to theoretical discussion ('Why honour the verse?', pp.57-60), to broad requirements of Shakespearean acting ('Acting Shakespeare's verse', pp.61113; 'Acting Shakespeare's prose', pp.168-192; 'Solo speeches', pp.193-257). Within the chapters are numerous practical exercises that the reader is encouraged to undertake while reading the book. These are helpfully indexed so that they may be quickly found and explored. It is 
therefore more possible to jump around the text, finding specific tools for specific situations. However, it is clear that each chapter of the book builds on the previous, lays foundation for a subsequent chapter, or both. For this reason, the full efficacy of Hinds's text reveals itself in the cumulative weight of his theories and practices as they develop throughout the text.

There are a number of strengths to Hinds's approach to and presentation of Shakespearean performance. First among these is Hinds's recognition that while writing on theory and practice can be beneficial in the transmission of practical approaches to performance, this writing must be supplemented with individual, subjective experience of the material presented. It is not unusual that a book on practical performance techniques would encourage the reader to actually engage in the practices described, but Hinds takes this a step further. There are many places in the book where Hinds presents not only his own opinion of the strongest way to approach a piece of text, but several alternatives. Frequently, the reader is expected to explore these and other possible variations. Hinds avoids insisting on the rightness of one variation and instead asks the reader to make an individual aesthetic judgement of what he/she feels is most effective. This approach suggests a recognition that there is no single correct interpretation of Shakespearean text and that any approach to teaching Shakespearean performance must attempt to develop ownership of the practices in the service of individual artistic vision. That Hinds allows space for disagreement and contradiction is a key step in this process and one which more texts on performing Shakespeare should endeavour to deploy.

Beyond this, Acting Shakespeare's language is admirable in its thoroughness. The text ranges from basic exercises to highly complex ways of thinking about or approaching the performance of Shakespearean text. What is particularly 
noteworthy is that in the presentation of his ideas, Hinds offers original insights into what appear to be beginnerlevel exercises. In this way, even highly experienced and knowledgeable readers will encounter new ideas or practices throughout the entirety of the book. Related to this is Hinds's refusal to accept received wisdom about Shakespearean text without first ensuring that it stands up to scrutiny, allowing sustained interrogation into the theory and practice of Shakespearean performance.

One of the key challenges of a text like this is that it represents an attempt to translate practice into a written account or description. While Hinds is extremely successful in this regard, there are places where his written articulation of practice is less clear and precise than it could have been. Early in the text, Hinds argues that 'every human utterance is an explanation, a question, an order' and that 'when delivering lines, then, there are only three types of objective a character can have... "to explain", "to ask" or "to order"' (Hinds, 2015, p.3). In reading the rest of the book, I have taken this to mean that all actions an actor might play could be grouped into three broad categories (explanations, questions or orders). However, it is possible that a reader (particularly someone without a grounding in action- and objective-based acting) might believe Hinds is suggesting that all they need ever do in performance is explain, ask or order. Similarly, in articulating scansion, Hinds offers examples of what he considers mis-scanned lines (these are almost always lines with too many unstressed syllables in a row). He asks the reader to recognise how the text seems to 'skitter' and refers to this type of scansion as 'skidding' or 'skiddy' (Hinds, 2015, pp.65-68). While I am in complete agreement with Hinds's overarching point- that the rhythm and meter of iambic verse should be honoured- the language he uses is imprecise and seems to reflect personal feeling more than a fully articulated argument for or against a particular scansion choice. This section particularly stands out: it reads as more dogmatic and less clearly 
articulated than the rest of the book.

In spite of these comparatively minor issues, in writing Acting Shakespeare's language, Hinds has offered a major practical tool for actors, directors, students, teachers and Shakespeare aficionados. There is much within this text that will be beneficial regardless of the reader's level of knowledge or experience. If the reader has a grounding in action- and objective-based acting, this book could be considered a primary source of knowledge and practice in Shakespearean performance. Highly recommended.

\section{About the review author}

MARC SILBERSCHATZ is a lecturer in drama at the University of Sunderland. He holds a PhD from the University of St Andrews and the Royal Conservatoire of Scotland. His practice-led research focuses on developing contributions to rehearsal and performance practice that attempt to minimise pre-agreed-upon performance structure and divided consciousness in actors. Also a professional theatre director, he has staged (among other things) productions of fourteen Shakespeare plays in both the United States and the United Kingdom. 